\title{
KORNAI AND ANTI-EQUILIBRIUM
}

\author{
Steve KEEN
}

János Kornai's Anti-Equilibrium was ahead of its time when it was written, and even today, when system dynamics software is extensively used in engineering and other disciplines, it remains ahead of its time in economics, which is still hampered by the dominant equilibrium-dominated modeling approach and the subjective beliefs that the truly sterile state of equilibrium is preferable to the real dynamic instability of actual capitalism. I show that the dead-end in which economic theory finds itself today is easily escaped if we adopt the system dynamics approach Kornai recommended in 1971, and derive macroeconomics directly from the structure of the macroeconomy.

Keywords: economic dynamics, system dynamics, complexity economics, complex systems, economic methodology, history of economic thought, economic simulation

JEL classification indices: C61, C62, C63, C69, C88

Steve Keen, Professor of Economics at the School of Social and Behavioural Sciences, Kingston University London. E-mail: debunking@gmail.com, www.profstevekeen.com 
"Our book is profoundly opposed to the viewpoint that equilibrium is good ... what is desirable is not that demand and supply should be in equilibrium but that ... one form of disequilibrium, namely pressure, should assert itself at a high degree of intensity. The marriage between an impotent man and a frigid woman may be considered as some form of 'equilibrium' - nevertheless, it can hardly be considered the ideal form of relationship between the two sexes. An intensive clash between opposed forces - a passionate one, we might say - is highly preferable to a half-hearted 'state of equilibrium' in the economy"

(Kornai 1971: 309).

János Kornai was, as usual, far ahead of the game when, in 1965, he commenced work on what would become the book Anti-Equilibrium (Kornai 1971). This was only two years after the mathematical meteorologist Edward Lorenz published his ground-breaking paper "Deterministic Nonperiodic Flow" (Lorenz 1963), which gave birth to what is now called "Complex Systems Theory", and was originally called "Chaos Theory": the examination of systems which are in a permanent state of what economists refer to as "disequilibrium". It was also less than a decade after Jay Forrester invented, using pen and paper, the modeling technique now known as "System Dynamics" (Forrester 2003), and just four years after his book, "Industrial Dynamics", brought the field to the attention of a wide audience - including János Kornai (Kornai 1971: 370, note 25).

Modern neoclassicals, looking back on Kornai's critique, would doubtless see his criticisms as relevant to an approach they have long ago abandoned. The inputoutput oriented CGE ("Computable General Equilibrium") models - that Kornai specifically criticized because they were the dominant manifestation of equilibrium economics in the $1960 \mathrm{~s}$ - were supplanted by the attempted grand synthesis of microeconomics and macroeconomics in Real Business Cycle models (RBC) (Lucas 1972, 1976; Kydland - Prescott 1982). These were later generalized - in terms of microeconomic theory, via their reliance on models of "imperfect" as well as "perfect" competition - by so-called Dynamic Stochastic General Equilibrium (DSGE) models (Smets - Wouters 2007).

However, the concept of equilibrium remained central to these models, and this was the core of Kornai's criticism. Not only was equilibrium an inappropriate perspective from which to model capitalism, Kornai argued, it was also an undesirable state for an actual capitalist economy as well. And yet the focus of neoclassical macroeconomic modelers on the definition and characteristics of an equilibrium state inevitably biased them to see equilibrium as not merely a modeling tool, but a desirable state for the economy. As Kornai notes in the paragraph preceding the lead citation for this paper, 
"An economic theory will suggest normative viewpoints merely by the selection of the questions to be answered. When a school continues to scrutinize the conditions necessary for equilibrium to come about, the conditions necessary for that equilibrium to be stable and the conditions under which it meets various optimality criteria, then it inevitably suggests that equilibrium is desirable. If a hundred economists were asked whether it is good or bad for an economic system to be in equilibrium, ninety-nine will certainly answer that it is good" (Kornai 1971: 309).

It is stating the obvious to note that Anti-Equilibrium had no impact on the direction taken by the profession, which persisted with the concept of equilibrium as its organizing principle. That intellectual juggernaut crashed into the unforeseen event of the "Great Recession" a decade ago, evincing panic-driven responses from policy-makers (Paulson 2010: 261). However, theoretical economists, who were the real target audience for Kornai's work, reacted much like their own models of the economy: after an initial shock, they settled back into equilibrium once more.

Peter Ireland's early neoclassical reaction to the crisis is indicative here (Ireland 2010, 2011). He began promisingly, stating that "Indeed, the Great Recession's extreme severity makes it tempting to argue that new theories are required to fully explain it" (Ireland 2011: 31). However, in blithe ignorance of both the existence and the widespread use of system dynamics in management and engineering (Forrester 1995; Radzicki - Tauheed 2009), he then quipped that "Attempts to explain movements in one set of endogenous variables, like GDP and employment, by direct appeal to movements in another, like asset market valuations or interest rates, sometimes make for decent journalism but rarely produce satisfactory economic insights" (Ireland 2011: 32).

He went on to modify his own DSGE model - which had, needless to say, failed to anticipate the approach of the crisis he now purported to simulate - by increasing the scale of the "preference and technology shocks" that drove its behavior. He concluded that the Great Recession commenced because of "a series of adverse preference and technology shocks in roughly the same mix and of roughly the same magnitude as those that hit the United States at the onset of the previous two recessions" (Ireland 2011: 48).

What made this recession Great, he argued, was that these shocks continued and got larger - though curiously, only in the negative direction: "The string of adverse preference and technology shocks continued, however, throughout 2008 and into 2009. Moreover, these shocks grew larger in magnitude, adding substantially not just to the length but also to the severity of the great recession" (Ireland 2011: 48). 
A decade later, that confidence that a few tweaks to "preference and technology shocks" is all that is needed to bring DSGE models into accordance with the real world is, thankfully, starting to unravel. A key factor here has been the continuing over-estimation of post-crisis growth by neoclassical modelers. This overestimation was hard-wired into their equilibrium perspective, for two reasons.

Firstly, in an equilibrium-oriented system, a period of below-par performance caused by normally distributed exogenous shocks should be followed by a period of above-par performance, caused by the same underlying distribution of exogenous shocks. This was the logic behind the argument in 2009 by the then Chairman of the Council of Economic Advisers to the US President, that the severe recession of 2008 should be followed by a strong rebound (Lazear - Marron 2009). The centerpiece of this advice was a linear regression on past recessions and rebounds, which failed to consider a clear trend in that data for rebounds to become less strong over time (see Figure 1).

Secondly, since the dynamics of DSGE models are driven by the vision of the convergence of the economy, along an unstable (!) time path, to a future point of "bliss" (Ramsey 1928: 545), and most models assume by convention that this path includes (for the US and other advanced economies) the equilibrium values

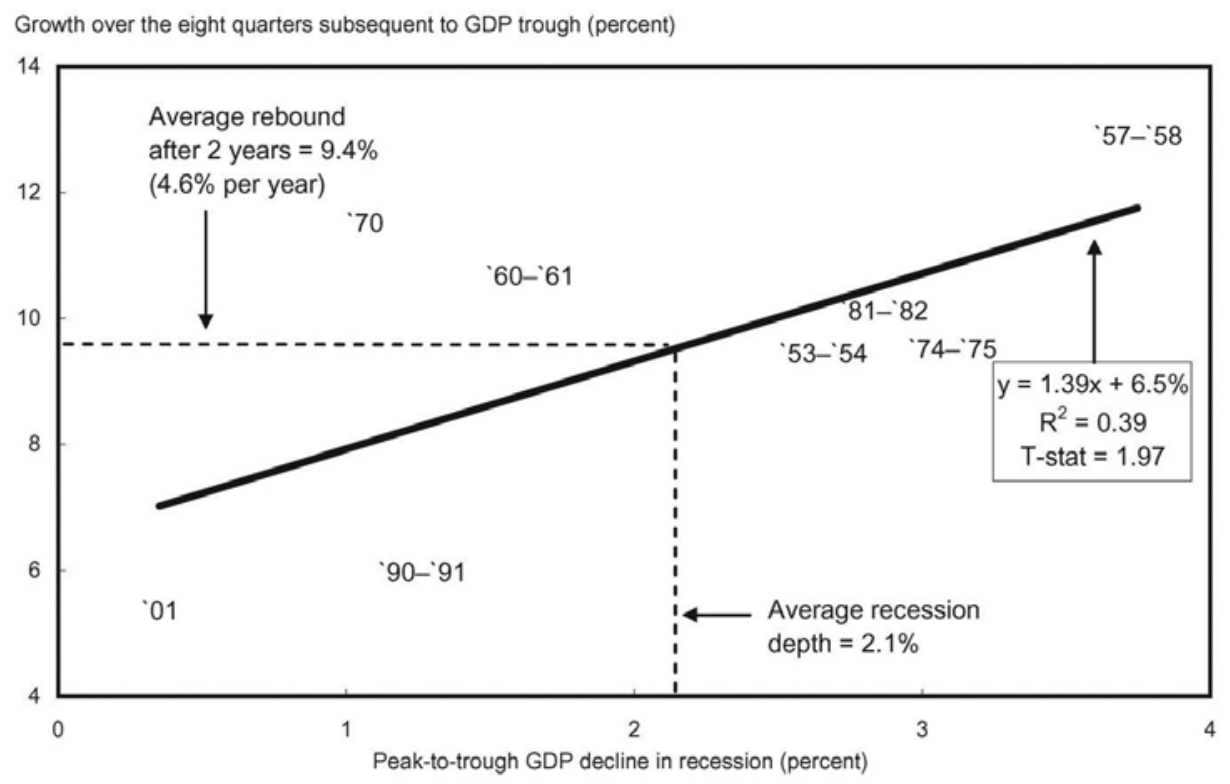

Figure 1. Recessions and recoveries in the US economy

Note: Data point labels indicate years of recession. The depth of recession is measured from the peak GDP quarter to the minimum GDP quarter. The recovery is the 8-quarter growth from that minimum GDP quarter.

Source: Author's calculations based on Department of Commerce (Bureau of Economic Analysis) data. 
of a 2 percent rate of inflation, a 3 percent rate of economic growth, and a 4 percent nominal interest rate, the models necessarily generate predictions of a timelagged return to these values.

A decade of forecasting failures in the same direction has arguably had more impact on the economics profession than the failure to anticipate the biggest economic crisis since the Great Depression, since one of their ancillary definitions of rationality is the absence of systemic errors in forecasts. This was clearly a major motivation behind a confluence of papers by leading neoclassical economists criticizing DSGE models and calling for change in economics in terms that, superficially, sound like Kornai himself from a half-century ago.

Kocherlakota, President of the Federal Reserve Bank of Minneapolis between 2010-2015, observed that "the premise of 'serious' modelling is that macroeconomic research can and should be grounded in an established body of theory ... after the highly surprising nature of the data flow over the past ten years, this basic premise of 'serious' modelling is wrong: we simply do not have a settled successful theory of the macroeconomy" (Kocherlakota 2016: 2).

Romer, now Chief Economist for the World Bank, satirized the DSGE belief that unspecified "preference and technology shocks" caused economic fluctuations by comparing them to Phlogiston, the fanciful "element" that chemists hypothesized to explain fire before Lavoisier (Romer 2016: 4). Ex-IMF Chief Economist Olivier Blanchard criticized DSGE models as being "based on unappealing assumptions. Not just simplifying assumptions, as any model must, but assumptions profoundly at odds with what we know about consumers and firms" (Blanchard 2016b: 1).

However, these rumblings of discontent are only superficially like Kornai's clarion call because they have not abandoned the belief in equilibrium as a core feature of both economic modelling and the economy itself. This is evident in Blanchard's follow-up paper, where he reacted to feedback from several commentators, including me (Keen 2016). Despite now displaying a commendable openness to criticism and alternative perspectives, Blanchard remains so embedded in the equilibrium method that he can read critics like me and not even see that we reject equilibrium methodology.

"A number of economists have recently written about the pros and cons of dynamic stochastic general equilibrium models (DSGEs). (Among them, and in addition to my own piece, are Narayana Kocherlakota, Simon WrenLewis, Paul Romer, Steve Keen, Anton Korinek, Paul Krugman, Noah Smith, Roger Farmer, and Brad Delong.) Here are my reactions to the debate: I believe that there is wide agreement on the following three propositions; let us not discuss them further, and move on: 1. Macroeconomics is about general equilibrium..." (Blanchard 2016a). 


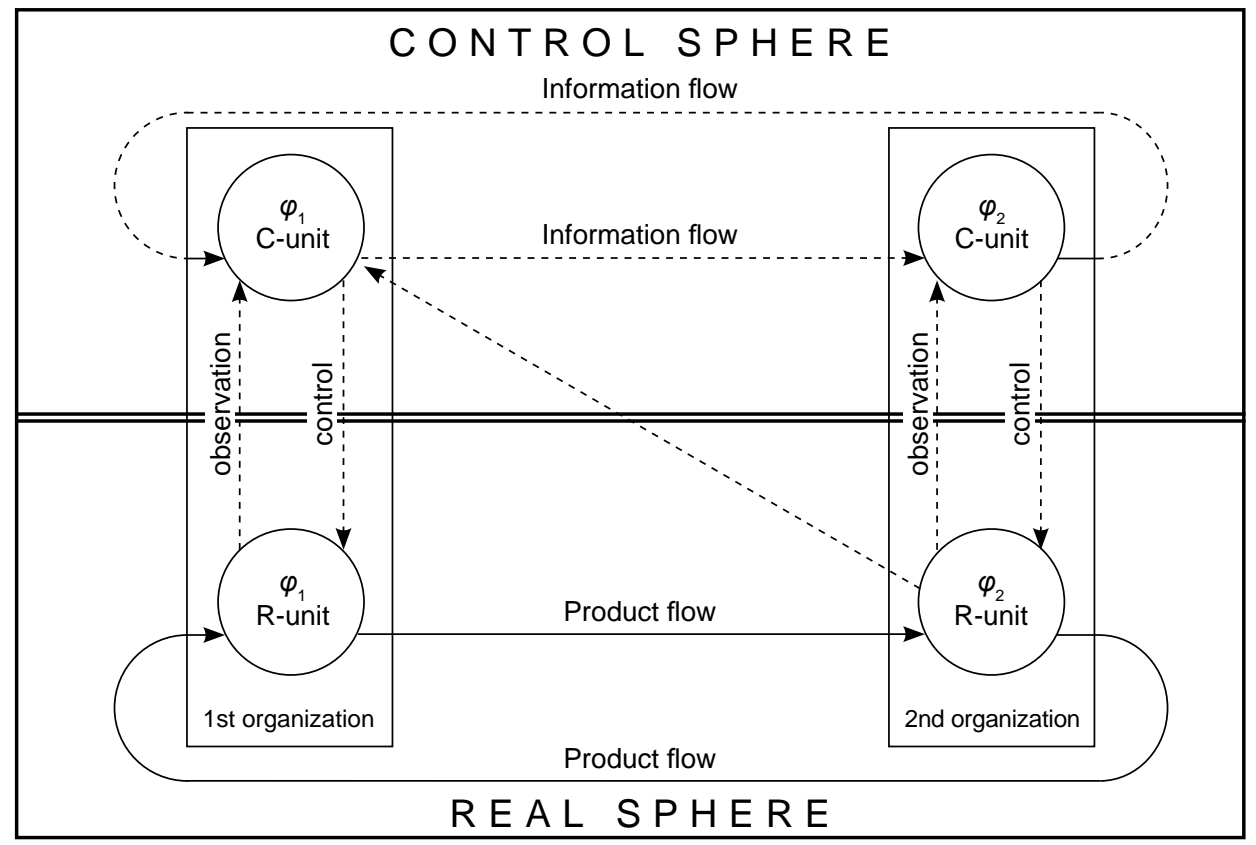

Figure 2. Kornai's specification of the real and the control sphere in Anti-Equilibrium Source: Kornai (1971: 41).

No, it is not! As Kornai argued half a century ago, economics in general is about evolutionary dynamics, and these phenomena cannot even be discussed from an equilibrium perspective. Evolutionary change occurs, not merely in the presence of equilibrium-disturbing forces, but under permanent far-from-equilibrium conditions. At the very least, macroeconomics should be about general far-from-equilibrium dynamics.

This raises the second component of Kornai's Anti-Equilibrium: the attempt to specify, in the form of general principles and mathematical notation, a system dynamics approach to economics. Here, as Kornai acknowledges, he was operating without the detailed knowledge of specialists in this field (Kornai 1971: 376). Also, at the time he wrote, generic system dynamics software did not exist, and the first great work of system dynamics, The Limits to Growth (Meadows et al. 1972), had not yet been published. Today there are many such programs, from engineering-oriented packages like Matlab's Simulink and solidThinking Embed SE (previously known as Vissim) to the management-oriented Vensim, Stella, iThink, and AnyLogic. 
Kornai's specification of what such programs should look like was not only prescient, but was in some ways in advance of what is on offer today. For example, his diagrams showed flows between entities in a dynamic model using wires that distinguished different forms of flows (see Figure 2).

This feature of distinguishing the type (or dimensions) of flows is not, to my knowledge, supported in any extant program today - though it is a design ambition of the system dynamics program I have designed for macroeconomics that I named Minsky, after another great economic iconoclast, Hyman Minsky.

These programs use flowcharts like Kornai's diagram to specify dynamic processes. As such, they are not specific to economics. The first model to usher in what was once called Chaos Theory and is now known as Complex Systems Theory, Lorenz's highly simplified model of fluid turbulence, illustrates two essential features of this field: the generation of aperiodic cycles from models that are completely deterministic (stochastic elements can be added, but are not necessary to generate cycles), and the structural simplicity of these models despite the complexity of the numerical simulations they produce. Lorenz's model consists of three ordinary differential equations with just three parameters:

$$
\begin{aligned}
& \frac{d x}{d t}=a \times(y-x) \\
& \frac{d y}{d t}=x \times(b-z)-y \\
& \frac{d z}{d t}=x \times y-c \times z \\
& \mathrm{a}=10, \mathrm{~b}=28, \mathrm{c}=2.67
\end{aligned}
$$

This extremely simple model was, of course, not just "plucked out of the aether", but was derived from far more complicated partial differential equations for fluid flow. Lorenz's objective in deriving it was to highlight the importance of nonlinear modelling to his fellow mathematical meteorologists at a time when linear models dominated this field. The equations thus fulfilled Kornai's criteria for being a real science, of both being logically sound and "a systematic description of the essential interrelations between the variables of reality" (Kornai 1971: 9). However, the equations had a third strength that was not apparent, even to Lorenz, before they were derived. In their simplicity, they uncovered an essential aspect of reality, which was previously regarded as a feature of a complicated system, rather than a simple one: the occurrence of complex, aperiodic cycles in a deterministic system. 
The technical reason for this strange behavior is that, for realistic values of the three parameters ( $a, b$ and $c$ ), the three equilibria of the model are both valid (they involve meaningful values of the system states $\mathrm{x}, \mathrm{y}$ and $\mathrm{z}$ ) and unstable. One equilibrium is an attractor along one of its dimensions, and a repeller along the other two. The other two are attractors along one dimension and cyclical repellers along the other two: from a distance they attract the system, but close up, they repel it in a cyclical way. The forces of attraction and repulsion depend on how close the system is to each equilibria: from a distance each is an attractor, while close up it is a repeller. The term "strange attractor" was invented to distinguish them from systems with stable equilibria.

The consequences of this dynamic structure are that firstly, the system generates cycles which never repeat - unlike the consistent cycles of ordinary harmonic oscillators - and secondly, the equilibria of the system define where the system will never be. This behavior uncovered a deep foundation for the inherently unstable dynamics of the weather that could not be discerned in the far more complicated partial differential equations of fluid dynamics from which it was derived. This discovery led to the rapid adoption of nonlinear modelling techniques in meteorology, with models that are far more complex than Lorenz's of course, but which begin with his foundation. We reap the benefits of this nonlinear, non-equilibrium revolution today, with meteorological forecasts that can generally accurately anticipate the weather a small but significant period in advance.

Is there an intellectual anagram of this model in economics: a simple model which is derived from incontrovertibly accepted first principles about economics, and which - though necessarily highly stylized - uncovers the cause of key empirical economic phenomena, and may, with more complicated models built on its foundations, enable us to forecast the economy with some reasonable accuracy for a relevant time period in advance?

The belief that DSGE models represented such a system and that it described a stable equilibrium path for the economy, in line with neoclassical dogma, was a major factor behind their rapid adoption, and the deep belief in them, by neoclassical economists before the crisis. As Robert Lucas put it, the belief that macroeconomics had to be derived from microeconomics, and that this would result in an incontrovertible basis for macroeconomics, and that this would lead to better control of the economy, were major motivating factors behind the development of firstly RBC and then DSGE models: "I also held on to Patinkin's ambition somehow, that the theory ought to be microeconomically founded, unified with price theory. I think this was a very common view ... Nobody was satisfied with IS-LM as the end of macroeconomic theorizing. The idea was we were going to tie it together with microeconomics and that was the job of our generation" (Lucas 2004: 20). 
The continuing belief that macroeconomics should be derived from undisputable foundations, and that this necessarily implies starting from microeconomics, are reasons why neoclassical economists still cling to their DSGE methodology, despite its failures to warn of the crisis, and to capture the behavior of the economy after it. As Blanchard put it, "The pursuit of a widely accepted analytical macroeconomic core, in which to locate discussions and extensions, may be a pipe dream, but it is a dream surely worth pursuing. If so, the three main modelling choices of DSGEs are the right ones. Starting from explicit microfoundations is clearly essential; where else to start from? Ad hoc equations will not do for that purpose..." (Blanchard 2016a: 3).

I concur with Blanchard's first proposition - as I believe does Kornai, too. Where Blanchard (and neoclassical economists in general) goes wrong is in believing that this necessarily implies his second proposition: that there is nowhere else to start from but microeconomics. Even if neoclassical microeconomics were empirically well-founded - which Kornai and I justifiably dispute (Kornai 1971, Chapters 10-11, 17-20; Keen 2011, Chapters 3-6) - the existence of "emergent properties" in complex systems makes this impossible. Physics Nobel Laureate Philip Anderson's seminal paper "More is Different", which was published at much the same time as Anti-Equilibrium, put this best: "The behaviour of large and complex aggregates of elementary particles, it turns out, is not to be understood in terms of a simple extrapolation of the properties of a few particles. Instead, at each level of complexity entirely new properties appear, and the understanding of the new behaviours requires research which I think is as fundamental in its nature as any other... Psychology is not applied biology, nor is biology applied chemistry" (Anderson 1972: 393).

Nor is macroeconomics "applied microeconomics": instead, macroeconomics must find its own foundations.

With Minsky (and also Kornai), I believe those foundations lie in induction from observation of the macroeconomy itself. Since the macroeconomy has suffered serious economic breakdowns in the past, our models of macroeconomics must, as Minsky declared, be able to replicate this incontrovertible fact of capitalist economies:

"Can 'It' - a Great Depression - happen again? And if 'It' can happen, why didn't 'It' occur in the years since World War II? These are questions that naturally follow from both the historical record and the comparative success of the past thirty-five years... To answer these questions it is necessary firstly to have an economic theory which makes great depressions one of the possible states in which our type of capitalist economy can find itself" (Minsky 1982: xii, xi). 
Secondly, taking my inspiration from Complex Systems Theory and System Dynamics, those foundations exist in the very structure of the macroeconomy itself. Since the macroeconomy is a complex system - one in which inherently nonlinear interactions occur between crucial parts of the system - then a simple specification of that system will uncover much of its behaviour. It is therefore conceivable that a meaningful macroeconomics can be derived directly from macroeconomic definitions themselves. It is then a question of which definitions should be used.

Two key macroeconomic definitions that all economists from all schools of thought would accept as macroeconomically significant are the employment rate and the distribution of income between capitalists and workers. ${ }^{1}$ These two can be defined as the number of people with a job (L) divided by the population $(\mathrm{N})$, and the wage bill (W) divided by GDP (Y):

$$
\begin{aligned}
& \lambda \equiv \frac{L}{N} \\
& \omega \equiv \frac{W}{Y}
\end{aligned}
$$

This gives us a two-dimensional foundation, but Complex Systems Theory tells us that the minimum number of dimensions needed to display complex behaviour is three ( $\mathrm{Li}$ - Yorke 1975). Following Minsky (1977) and Graziani (1989), I have always regarded private debt as the essential third dimension in macroeconomics (Keen 1995, 2015, 2017). Neoclassical economists routinely ignore the role of money and debt in capitalism, on the basis of the "Loanable Funds" model of banks as intermediaries (Tobin 1963), but this model has recently been called out as fallacious by the Bank of England (McLeay et al. 2014) and the Bundesbank (2017) - who thus support over five decades of research by non-mainstream economists into the macroeconomic consequences of bank originated money and debt (Fisher 1932, 1933; Schumpeter 1934; Holmes 1969; Moore 1979; Graziani 1989; Werner 2011). Adding the private debt to GDP ratio - and thus including Bankers as a separate social class to Workers and Capitalists - gives us a third dimension:

$$
d \equiv \frac{D}{Y}
$$

$1 \quad$ In a two-class system, defining $Y$ and $W$ necessarily also defines profit, $\Pi \equiv Y-W$.

2 This now requires a redefinition of income shares to include the fraction of GDP going to bankers $(B): \Pi \equiv Y-W-B$. The three income shares are now $\omega=W / Y, b_{s}=r \cdot D / Y$ and $\pi_{s}=1-\omega-b$. 
With the relationship between employment and output defined as $a \equiv Y / L$ and the wage bill defined as the wage rate times employment $W \equiv w \cdot L,{ }^{3}$ we now have sufficient terms to derive a set of true-by-definition statements about the fundamental dynamics of a capitalist economy:

- employment will rise if economic growth exceeds the sum of population \& labor productivity growth,

- wages share of output will rise if wage rise exceeds growth in labor productivity,

- the debt ratio will rise if debt grows faster than GDP.

Stated as equations, these are:

$$
\begin{aligned}
\hat{\lambda} & \equiv \hat{Y}-(\hat{a}+\hat{N}) \\
\hat{\omega} & \equiv \hat{w}-\hat{a} \\
\hat{d} & \equiv \hat{D}-\hat{Y}
\end{aligned}
$$

Deriving a model from these definitions requires postulating some relationships between them. Here Complex Systems Theory tells us that the precise details of such hypothesized relationships are less important than the relationships themselves. So long as some generally realistic relationship is postulated - for example, assuming a higher level of employment generally makes it easier for workers to achieve wage rises - then the model will generate the fundamental characteristics of the system it is describing. More realism can be added later by replacing simple relationships with more realistic ones, but the basic realism arises from getting the structure of the model right in the first place.

With that in mind, the first model shown here assumes:

- A simple linear relationship between industrial capacity (K) and output (Y), with change in capacity being gross investment minus depreciation:

$$
Y=\frac{K}{v}, \frac{d}{d t} K=I_{G}-\delta \cdot K
$$

- Wage demands are a linear function of the employment rate:

$$
w_{c h}=\hat{w}=\lambda_{S} \cdot\left(\lambda-\lambda_{Z}\right)
$$

3 These two steps are the only ones involving any actual assumptions, that of a uniform level of labor productivity and a uniform wage.

$4 \quad$ Here $\hat{x} \equiv \frac{1}{x} \cdot \frac{d x}{d t}$. 
- Investment as a fraction of GDP $i_{G}=I_{G} / Y$ is a linear function of the rate of profit:

$$
i_{G}=\pi_{S} \cdot\left(\pi_{r}-\pi_{Z}\right), \pi_{r}=\frac{Y-W-B}{K}
$$

- Investment in excess of profit is financed by borrowing, and bankers' income equals the real interest rate spread times outstanding debt:

$$
\frac{d}{d t} D=I_{G}-\Pi, B=r \cdot D
$$

- Finally, constant growth in labor productivity and population is assumed:

$$
\hat{a}=\alpha, \hat{N}=\beta
$$

This results in the following 3-dimensional dynamic model, which has inherent nonlinearities whenever one system state $(\lambda, \omega, d)$ is multiplied by itself or another, even though the behavioral relations in the model are all linear:

$$
\begin{aligned}
\frac{d}{d t} \lambda & =\lambda \cdot\left(\frac{i_{G}}{v}-(\alpha+\beta+\delta)\right) \\
\frac{d}{d t} \omega & =\omega \cdot\left(w_{c h}-\alpha\right) \\
\frac{d}{d t} d & =i_{G}-\pi_{s}-d \cdot\left(\frac{i_{G}}{v}-\delta\right) \\
i_{G} & =\pi_{S} \cdot\left(\pi_{r}-\pi_{Z}\right) \\
w_{c h} & =\lambda_{S} \cdot\left(\lambda-\lambda_{Z}\right) \\
\pi_{r} & =\frac{\pi_{s}}{v}
\end{aligned}
$$

This model has two significant equilibria, ${ }^{5}$ and unlike the Lorenz model, these are attractors for different parameter values (though their stability also depends upon initial conditions). Grasselli and Costa Lima have characterized as the "good" equilibrium (Grasselli - Costa Lima 2012: 208) with positive employment and wages share of GDP, and a finite debt to GDP ratio; the other is the "bad" equilibrium with zero employment and wages share of GDP and an infinite debt ratio. ${ }^{6}$

5 See Graselli - Costa Lima (2012) for a full discussion.

6 The basic model does not include bankruptcy, so debt compounds forever once profits become permanently negative given debt service costs. This extreme outcome can be attenuated in extensions by allowing for bankruptcy, government spending, etc. 
However, despite having stable equilibria, the model still displays a form of strange attractor behaviour known as the "Intermittent Route to Chaos" (Pomeau - Manneville 1980). This was discovered, like Lorenz's original model, in studies of fluid turbulence: an experiment would appear to show a transition from turbulence to laminar flow, only for turbulence to suddenly appear again.

The behavior of the system can be characterized by a "Poincare Map" showing a dynamic process bouncing between a curve and a straight line. For values where the curve and straight line intersect, there are two equilibria, with the lower-valued one being stable. This convergence to the "good equilibrium", with a constant employment rate, wages share of GDP, and debt to GDP ratio can be nicely followed in a simulation model. ${ }^{7}$ For higher values of the relevant parameter, the curve and the line do not intersect. This leads to the phenomenon, in fluid dynamics, of a transition from turbulent to laminar flow, followed by subsequent turbulent flow.

This behavior is replicated in this simple economic model (see Figure 6). With a higher value of a key parameter - in this case, $\pi_{\mathrm{S}}$, the slope of the capitalist investment function (Equation (10)) - the system appears to converge towards the good equilibrium, but then diverges and collapses towards the unfortunately stable bad equilibrium. A key driving factor here is the debt to GDP ratio, which does not stabilize but continues to grow in a cyclical manner.

Though this model is highly stylized, this peculiar phenomenon of an apparent transition from instability to stability before yet more instability appeared in the real world as well, where the initial decline in volatility was christened "The Great Moderation" by equilibrium-oriented mainstream economists who saw it as a "welcome change in the economy" (Bernanke 2000: 24), rather than what it actually was, a "lull before the storm" (Keen 1995: 634) (see Figure 3).

Two other phenomena generated by this model also appeared in the real world: an increase in the private debt to GDP ratio (see Figure 4), and an increase in inequality: the rising bankers share affects not the capitalist income share but the workers' (prior to the ultimate collapse in which capitalist share goes negative). In the model, all four phenomena - a rising debt to GDP ratio, a period of diminishing cycles, a subsequent crisis, and rising inequality - are causally related in a complex systems manner. ${ }^{8}$

This model is only the first pass in a program to derive a realistic macroeconomics. Many further elements could be added in a fashion similar to that outlined by Kornai, where initial generalizations - for example, treating GDP as a timevarying scalar in this model - are replaced by more realistic vector definitions. 


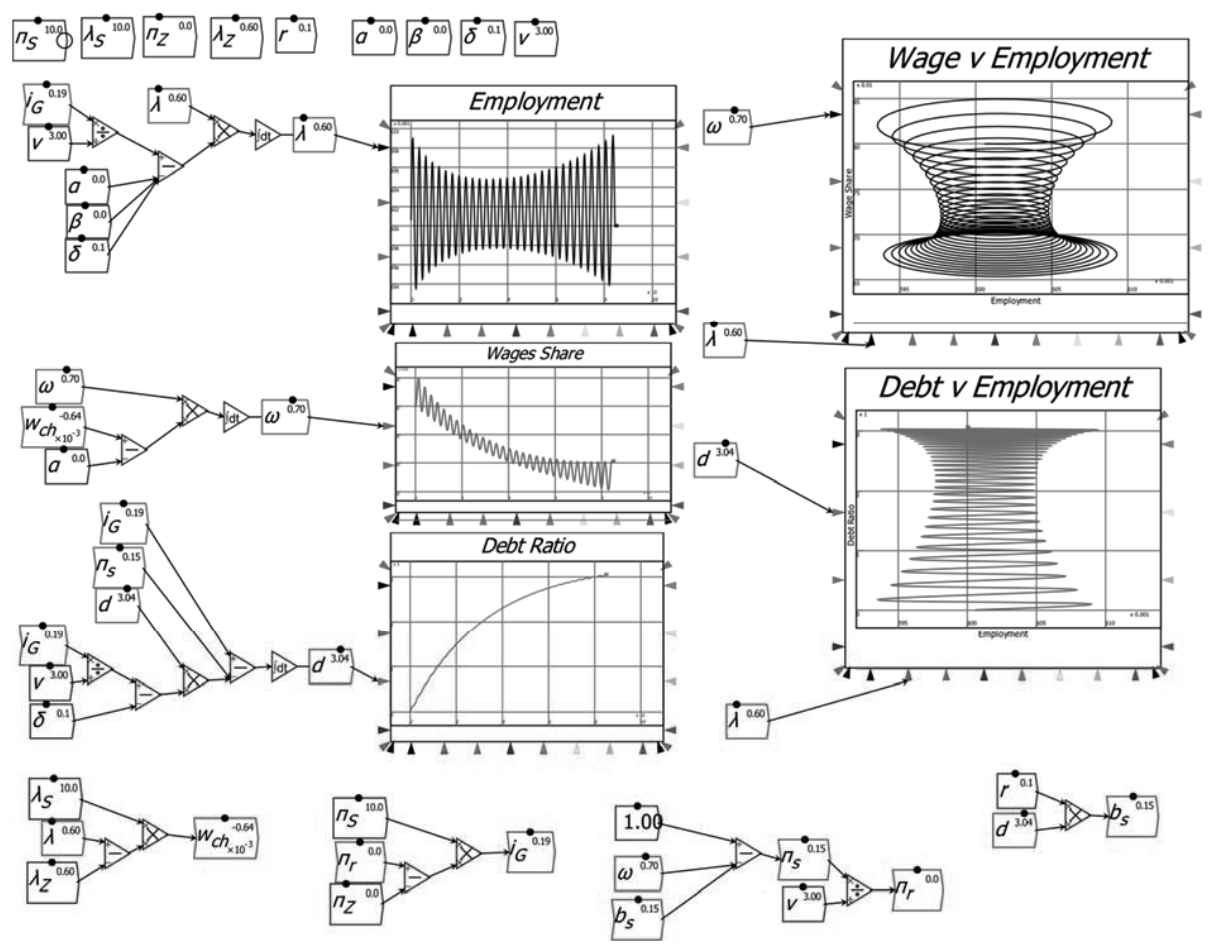

Figure 3. Apparent moderation in volatility followed by more volatility and crisis

Government can be introduced and has been (Keen 1995: 625-632), banks and monetary dynamics can be added (the main feature of Minsky that distinguishes it within the system dynamics family is the capacity to model financial flows easily using double-entry book-keeping tables named Godley Tables - in honor of Wynne Godley -, Ponzi as well as real investing can be considered (Grasselli Costa Lima 2012), international trade and financial flows can be incorporated.

As Kornai himself remarked at the end of Anti-Equilibrium, "The time is ripe for a further synthesis" (Kornai 1971: 373).

\section{THE FUTURE?}

The note of optimism on which Kornai ended in 1971 was clearly not borne out by subsequent events. The equilibrium theory he correctly critiqued almost five decades ago was replaced by an even more extreme and virulent variant, while genuinely science-based disciplines like meteorology and engineering made 


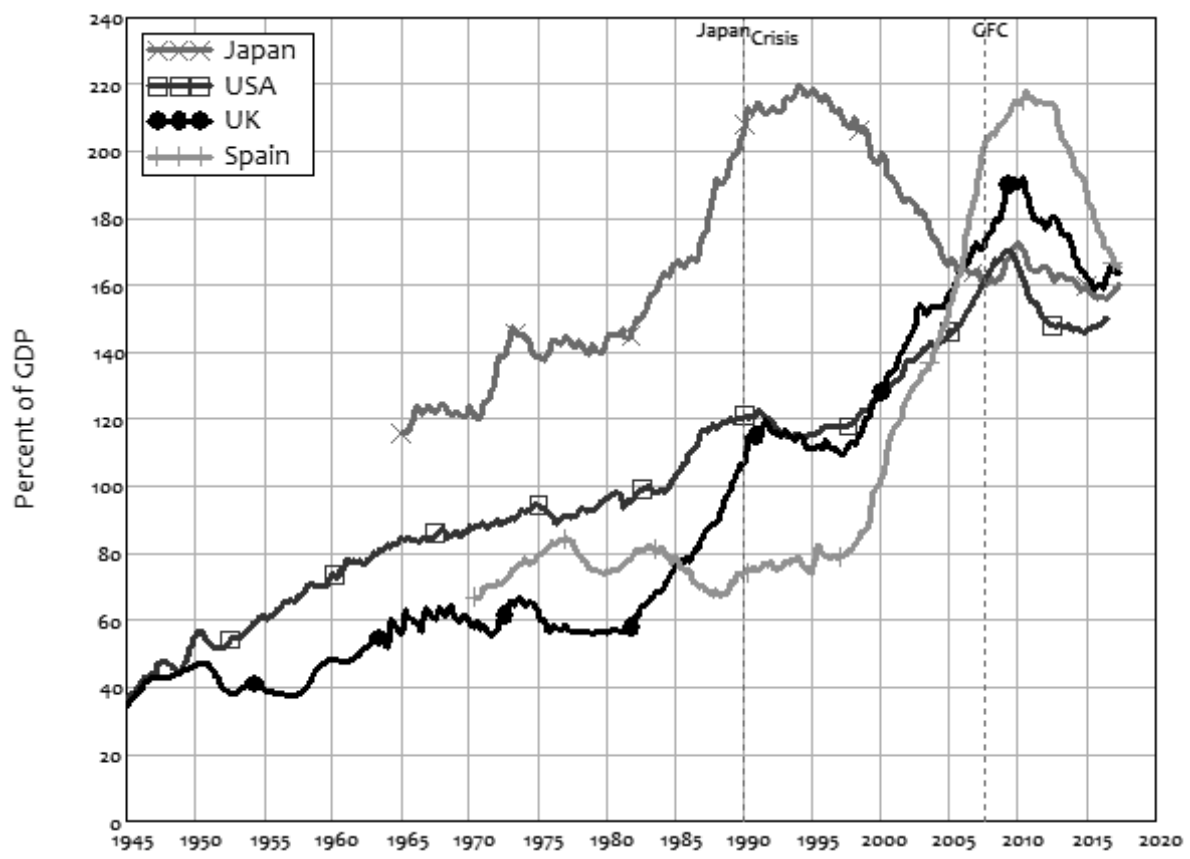

Figure 4. Rising private debt to GDP ratios prior to economic crises

Source: BIS data.

enormous advances by applying much the same techniques that Kornai favored for economics.

Is the time for a further synthesis riper now? Clearly, one pre-requisite for it exists that was not present when Kornai wrote Anti-Equilibrium: equilibriumoriented economics made spectacularly wrong forecasts about the economy, both before the crisis in 2008 and after it. Economists are still congenitally biased towards thinking of the economy in equilibrium terms, but a public and a political class that once trusted their judgment, simply on the basis that one should trust "the experts", is less willing to do so after such spectacular failures.

A second also exists: the modelling approach that Kornai recommended is now no longer hypothetical, but exists in many software packages, including Minsky.

The main stumbling block remains the extent to which economists of all persuasions - and not merely the neoclassicals - are infected with the belief in or the unaware practice of equilibrium modelling. Post-Keynesian stock-flow consistent modelling, which is an enormous advance on neoclassical macroeconomics simply because it treats capitalism as the inherently monetary system it is rather than pretending it is a barter system, is still dominated by the practice of hitting 
the model with a shock and then analyzing the time path of its return to a new equilibrium. The vast majority of such systems are also linear, and therefore cannot capture the inherently nonlinear dynamics of an actual capitalist system.

The primary reason for this is another factor that Kornai identifies, that economists have in general been taught mathematics by other economists, and not by actual mathematicians:

"Economics must break away from the narrow framework of its present mathematical apparatus. It seems this will only be achieved with the cooperation of professional mathematicians who are well versed in many branches of mathematics ... even the best prepared mathematical economists are usually narrow and their mathematical knowledge is limited: they are versed on a higher level only in the mathematical disciplines traditionally employed in economics" (Kornai 1971: 360-361).

In order to finally escape from the trap of equilibrium thinking, economists also need to explore the work of other neglected pioneers in dynamic and evolutionary economics in addition to Kornai: Schumpeter, who, like Kornai, saw disequilibrium as a virtue in economics rather than a vice (Schumpeter 1934); Minsky, who likewise saw capitalism as an inherently non-equilibrium system and warned, as Schumpeter did not, of the dangers of financial instability (Minsky 1982); Goodwin, who, more than any other economist, mastered the development of nonlinear dynamics (Goodwin 1967, 1990); and the today-forgotten visionary, applied mathematician turned Post-Keynesian economist John Blatt.

I began with a long quote from Kornai, and I will end with one from Blatt which has long echoed in my mind, and which is very consonant with Kornai's views. Writing a decade after Kornai (whom, by the way, he cited: Blatt 1983a: 14, note 7), Blatt observed that "The bicentenary of The Wealth of Nations has passed, and so has the centenary of the neoclassical revolution in economics. Yet the present state of dynamic economic theory leaves very much to be desired and appears to show little sign of significant improvement in the near future ... it is impossible to ignore the passage of two hundred years. A baby is expected to first crawl, then walk, before running. But what if a grown-up man is still crawling? At present, the state of our dynamic economics is more akin to a crawl than to a walk, to say nothing of a run. Indeed, some may think that capitalism as a social system may disappear before its dynamics are understood by economists" (Blatt 1983a: 4-5). 


\section{REFERENCES}

Anderson, P. W. (1972): More Is Different. Science, 177(4047): 393-396.

Bernanke, B. S. (2000): Essays on the Great Depression. Princeton: Princeton University Press.

Blanchard, O. (2016a): Do DSGE Models Have a Future? https://piie.com/system/files/documents/ pb16-11.pdf.

Blanchard, O. (2016b): Further Thoughts on DSGE Models: What We Agree on and What We do Not. Realtime Economic Issues Watch. Peterson Institute for International Economics.https:// piie.com/blogs/realtime-economic-issues-watch/further-thoughts-dsge-models.

Blatt, J. M. (1983a): Dynamic Economic Systems: A Post-Keynesian Approach. Armonk, N.Y.: M.E. Sharpe.

Blatt, J. M. (1983b): Economic Policy and Endogenous Cycles. Journal of Post Keynesian Economics, 5(4): 635-647.

Deutsche Bundesbank (2017): How Money is Created. Frankfurt am Main. http://www.bundesbank.de/Redaktion/EN/Topics/2017/2017_04_25_how_money_is_created.html.

Fisher, I. (1932): Booms and Depressions: Some First Principles. New York: Adelphi.

Fisher, I. (1933): The Debt-Deflation Theory of Great Depressions. Econometrica, 1(4): 337-357.

Forrester, J. W. (1995): The Beginning of System Dynamics. The McKinsey Quarterly, 4.

Forrester, J. W. (2003): Dynamic Models of Economic Systems and Industrial Organizations: Note to the Faculty Research Seminar. (From Forrester, J. W. November 5, 1956.) System Dynamics Review, 19(4): 329-345.

Goodwin, R. M. (1967): A Growth Cycle. In: Feinstein, C. H.: Socialism, Capitalism and Economic Growth. Cambridge: Cambridge University Press, pp. 54-58.

Goodwin, R. M. (1990): Chaotic Economic Dynamics. Oxford: Oxford University Press.

Grasselli, M. - Costa Lima, B. (2012): An Analysis of the Keen Model for Credit Expansion, Asset Price Bubbles and Financial Fragility. Mathematics and Financial Economics, 6(3): 191-210.

Graziani, A. (1989): The Theory of the Monetary Circuit. Greenwich Political Economic Research Centre, Thames Papers in Political Economy, Spring: 1-26.

Holmes, A. R. (1969): Operational Constraints on the Stabilization of Money Supply Growth. In: Morris, F. E. (ed.): Controlling Monetary Aggregates. Nantucket Island, The Federal Reserve Bank of Boston: pp. 65-77.

Ireland, P. (2010): A New Keynesian Perspective on the Great Recession. Boston College Working Papers in Economics, No. 735.

Ireland, P. N. (2011): A New Keynesian Perspective on the Great Recession. Journal of Money, Credit, and Banking, 43(1): 31-54.

Keen, S. (1995): Finance and Economic Breakdown: Modeling Minsky's 'Financial Instability Hypothesis. Journal of Post Keynesian Economics, 17(4): 607-635.

Keen, S. (2011): Debunking Economics: The Naked Emperor Dethroned? London: Zed Books.

Keen, S. (2015): Post Keynesian Theories of Crisis. American Journal of Economics and Sociology, 74(2): 298-324.

Keen, S. (2016): The Need for Pluralism in Economics. Steve Keen's Debtwatch http://www.debtdeflation.com/blogs/2016/08/13/the-need-for-pluralism-in-economics/.

Keen, S. (2017): Can We Avoid Another Financial Crisis? (The Future of Capitalism). London: Polity Press.

Kocherlakota, N. (2016): Toy Models. https://docs.google.com/viewer?a=v\&pid=sites\&srcid=ZGV mYXVsdGRvbWFpbnxrb2NoZXJsYWtvdGEwMD18Z3g6MTAyZmIzODcxNGZiOGY4Yg.

Kornai, J. (1971): Anti-Equilibrium: On Economic Systems Theory and the Tasks of Research. Amsterdam: North-Holland. 
Kydland, F. E. - Prescott, E. C. (1982): Time to Build and Aggregate Fluctuations. Econometrica, 50(6): 1345-1370.

Lazear, E. P. - Marron, D. B. (2009): Economic Report of the President. Council of Economic Advisers. Washington, D. C. : United States Government Printing Office.

Li, T. Y. - Yorke, J. A. (1975): Period Three Implies Chaos. The American Mathematical Monthly, 82(10): 985-992.

Lorenz, E. N. (1963): Deterministic Nonperiodic Flow. Journal of the Atmospheric Sciences, 20(2): $130-141$.

Lucas, R. E. Jr. (1972): Econometric Testing of the Natural Rate Hypothesis. The Econometrics of Price Determination Conference, October 30-31 1970. Washington, D.C., Board of Governors of the Federal Reserve System and Social Science Research Council, pp. 50-59.

Lucas, R. E. Jr. (1976): Econometric Policy Evaluation: A Critique. Carnegie-Rochester Conference Series on Public Policy, 1(1): 19-46.

Lucas, R. E. Jr. (2004): Keynote Address to the 2003 HOPE Conference: My Keynesian Education. History of Political Economy, 36: 12-24.

McLeay, M. - Radia, A. - Thomas, R. (2014): Money Creation in the Modern Economy. Bank of England Quarterly Bulletin, 2014 Q1: 14-27.

Meadows, D. H. - Randers, J. - Meadows, D. (1972): The Limits to Growth. New York: Universe Books.

Minsky, H. P. (1977): The Financial Instability Hypothesis: An Interpretation of Keynes and an Alternative to 'Standard' Theory. Nebraska Journal of Economics and Business, 16(1): 5-16.

Minsky, H. P. (1982): Can “It” Happen Again? Essays on Instability and Finance. Armonk, N.Y.: M. E. Sharpe.

Moore, B. J. (1979): The Endogenous Money Stock. Journal of Post Keynesian Economics, 2(1): 49-70.

Paulson, H. M. (2010): On the Brink: Inside the Race to Stop the Collapse of the Global Financial System. New York: Business Plus.

Pomeau, Y. - Manneville, P. (1980): Intermittent Transition to Turbulence in Dissipative Dynamical Systems. Communications in Mathematical Physics, 74: 189-197.

Radzicki, M. J. - Tauheed, L. (2009): In Defense of System Dynamics: A Response to Professor Hayden. Journal of Economic Issues, 43(4): 1043-1061.

Ramsey, F. P. (1928): A Mathematical Theory of Saving. The Economic Journal, 38(152): 543559.

Romer, P. (2016): The Trouble with Macroeconomics. Working Paper.

Schumpeter, J. A. (1934): The Theory of Economic Development : An Inquiry into Profits, Capital, Credit, Interest and the Business Cycle. Cambridge, MA: Harvard University Press.

Smets, F. - Wouters, R. (2007): Shocks and Frictions in US Business Cycles: A Bayesian DSGE Approach. American Economic Review, 97(3): 586-606.

Tobin, J. (1963): Commercial Banks as Creators of "Money". In: Carson, D. (ed.): Banking and Monetary Studies. Homewood, Ill.: D. Irwin Inc., pp. 408-419.

Werner, R. (2011): Economics as if Banks Mattered: A Contribution Based on the Inductive Methodology. Manchester School, 79(SUPPL.2): 25-35. 


\section{APPENDIX}

Deriving dynamic equations for $(\hat{\lambda}, \hat{\omega}, \hat{d})$ :

$$
\begin{aligned}
& \lambda \equiv \frac{L}{N} \\
& \frac{d}{d t} \lambda \equiv \frac{d}{d t}\left(\frac{L}{N}\right) \\
& \equiv \frac{1}{N} \frac{d}{d t} L-\left(\frac{L}{N}\right) \cdot \frac{1}{N} \cdot \frac{d}{d t} N \\
& \equiv \frac{1}{N} \frac{d}{d t} \frac{Y}{a}-\lambda \cdot \hat{N} \\
& \equiv \frac{1}{N}\left(\frac{1}{a} \frac{d}{d t} Y-\frac{Y}{a} \frac{1}{a} \frac{d}{d t} a\right)-\lambda \cdot \hat{N} \\
& \equiv \frac{1}{N}\left(\frac{1}{a} \frac{Y}{Y} \frac{d}{d t} Y\right)-\lambda \cdot(\hat{a}+\hat{N}) \\
& \hat{\lambda} \equiv \hat{Y}-(\hat{a}+\hat{N}) \\
& \omega \equiv \frac{W}{Y} \\
& \frac{d}{d t} \omega \equiv \frac{d}{d t}\left(\frac{W}{Y}\right) \\
& \equiv \frac{d}{d t}\left(\frac{w \cdot L}{L \cdot a}\right) \\
& \equiv \frac{d}{d t}\left(\frac{w}{a}\right) \\
& \equiv \frac{1}{a} \frac{d}{d t} w-\frac{w}{a} \cdot \frac{1}{a} \cdot \frac{d}{d t} a \\
& \equiv \hat{w}-\hat{a} \\
& \\
&
\end{aligned}
$$




$$
\begin{aligned}
d & \equiv \frac{D}{Y} \\
\frac{d}{d t} d & \equiv \frac{d}{d t}\left(\frac{D}{Y}\right) \\
& \equiv \frac{1}{Y} \frac{d}{d t} D-\frac{D}{Y} \cdot \frac{1}{Y} \frac{d}{d t} Y \\
& \equiv \frac{1}{Y} \frac{D}{D} \frac{d}{d t} D-d \cdot \hat{Y} \\
& \equiv d \cdot \frac{1}{D} \frac{d}{d t} D-d \cdot \hat{Y} \\
\hat{d} & \equiv \hat{D}-\hat{Y}
\end{aligned}
$$

